\title{
Undoped and in-situ B doped GeSn epitaxial growth on Ge by atmospheric pressure- chemical vapor deposition
}

Vincent, B.; Gencarelli, F.; Bender, H.; Merckling, C.; Douhard, B.; Petersen, Dirch Hjorth; Hansen, Ole; Henrichsen, H. H.; Meersschaut, J.; Vandervorst, W.

Total number of authors:

13

Published in:

Applied Physics Letters

Link to article, DOI:

$10.1063 / 1.3645620$

Publication date:

2011

Document Version

Publisher's PDF, also known as Version of record

Link back to DTU Orbit

Citation (APA):

Vincent, B., Gencarelli, F., Bender, H., Merckling, C., Douhard, B., Petersen, D. H., Hansen, O., Henrichsen, H. H., Meersschaut, J., Vandervorst, W., Heyns, M., Loo, R., \& Caymax, M. (2011). Undoped and in-situ B doped GeSn epitaxial growth on Ge by atmospheric pressure-chemical vapor deposition. Applied Physics Letters, 99(15), 152103. https://doi.org/10.1063/1.3645620

\section{General rights}

Copyright and moral rights for the publications made accessible in the public portal are retained by the authors and/or other copyright owners and it is a condition of accessing publications that users recognise and abide by the legal requirements associated with these rights.

- Users may download and print one copy of any publication from the public portal for the purpose of private study or research.

- You may not further distribute the material or use it for any profit-making activity or commercial gain

- You may freely distribute the URL identifying the publication in the public portal 


\section{AD Applied Physics \\ Letters \\ Undoped and in-situ B doped GeSn epitaxial growth on Ge by atmospheric pressure-chemical vapor deposition}

B. Vincent, F. Gencarelli, H. Bender, C. Merckling, B. Douhard et al.

Citation: Appl. Phys. Lett. 99, 152103 (2011); doi: 10.1063/1.3645620

View online: http://dx.doi.org/10.1063/1.3645620

View Table of Contents: http://apl.aip.org/resource/1/APPLAB/v99/i15

Published by the American Institute of Physics.

\section{Related Articles}

Enhanced thermoelectric figure of merit in SiGe alloy nanowires by boundary and hole-phonon scattering J. Appl. Phys. 110, 074317 (2011)

Investigation on p-type lithium niobate crystals

AlP Advances 1, 032171 (2011)

Magnesium, nitrogen codoped Cr2O3: A p-type transparent conducting oxide

Appl. Phys. Lett. 99, 111910 (2011)

GaSe1xSx and GaSe1xTex thick crystals for broadband terahertz pulses generation

Appl. Phys. Lett. 99, 081105 (2011)

Microwave absorption properties of MWCNT-SiC composites synthesized via a low temperature induced reaction AlP Advances 1, 032140 (2011)

\section{Additional information on Appl. Phys. Lett.}

Journal Homepage: http://apl.aip.org/

Journal Information: http://apl.aip.org/about/about_the_journal

Top downloads: http://apl.aip.org/features/most_downloaded

Information for Authors: http://apl.aip.org/authors

\section{ADVERTISEMENT}

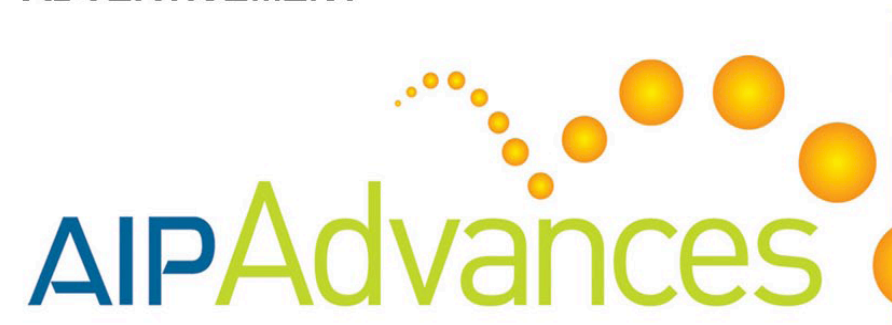

Submit Now

\section{Explore AIP's new \\ open-access journal}

Article-level metrics now available

Join the conversation!

Rate \& comment on articles 


\title{
Undoped and in-situ B doped GeSn epitaxial growth on Ge by atmospheric pressure-chemical vapor deposition
}

\author{
B. Vincent, ${ }^{1, a)}$ F. Gencarelli, ${ }^{1, b)}$ H. Bender, ${ }^{1}$ C. Merckling, ${ }^{1}$ B. Douhard, ${ }^{1}$ D. H. Petersen, ${ }^{2}$ \\ O. Hansen, ${ }^{2}$ H. H. Henrichsen, ${ }^{3}$ J. Meersschaut, ${ }^{1}$ W. Vandervorst, ${ }^{1, c)}$ M. Heyns, ${ }^{1, d)}$ R. Loo, ${ }^{1}$ \\ and M. Caymax ${ }^{1}$ \\ ${ }^{1}$ IMEC, Kapeldreef 75, Leuven B-3001, Belgium \\ ${ }^{2}$ Department of Micro- and Nanotechnology, Technical University of Denmark, DTU Nanotech, \\ Building 345B, DK-2800 Kgs. Lyngby, Denmark \\ ${ }^{3}$ CAPRES A/S, Scion-DTU, Building 373, DK-2800 Kgs. Lyngby, Denmark
}

(Received 13 July 2011; accepted 12 September 2011; published online 11 October 2011)

\begin{abstract}
In this letter, we propose an atmospheric pressure-chemical vapor deposition technique to grow metastable GeSn epitaxial layers on Ge. We report the growth of defect free fully strained undoped and in-situ B doped GeSn layers on Ge substrates with Sn contents up to 8\%. Those metastable layers stay fully strained after $30 \mathrm{~min}$ anneal in $\mathrm{N}_{2}$ at $500{ }^{\circ} \mathrm{C}$; Ge-Sn interdiffusion is seen at $500^{\circ} \mathrm{C}$ but not at lower temperature. $\mathrm{B}$ is $100 \%$ active in the in-situ GeSn:B layers up to a concentration of $1.7 \times 10^{19} \mathrm{~cm}^{-3}$. GeSn:B provides slightly lower Hall hole mobility values than in pure p-type Ge especially for low B concentrations. (C) 2011 American Institute of Physics. [doi:10.1063/1.3645620]
\end{abstract}

GeSn has received many interests in the last 10 years for various applications. ${ }^{1-3}$ An indirect to direct bandgap transition is theoretically expected for about $10 \% \mathrm{Sn}$ in $\mathrm{GeSn}^{4} \mathrm{Sn}$ having about $13 \%$ lattice mismatch with $\mathrm{Ge}, \mathrm{GeSn}$ alloys can offer interesting new routes for stress implementation: (1) tensely biaxial strained Ge layers ${ }^{5}$ on $\mathrm{GeSn}$ provides a direct bandgap and an enhanced electron mobility with respect to unstrained Ge, (2) compressively biaxial strained GeSn layers grown on Ge can provide a strained quantum well architecture for advanced metal oxide semiconductor field effect transistors, ${ }^{6}$ and (3) GeSn can be used moreover as a source/drain stressor materials for advanced Ge pMOSFET technology. ${ }^{7}$

Sn solubility in the Ge matrix is however very poor ${ }^{8}$ (less than $1 \%$ ). Based on this thermodynamics limitation, the first monocrystalline GeSn growth techniques developed were based on out of equilibrium growth conditions using ultimately low temperatures and reduced pressures. 9,10 Whereas the necessity of growing GeSn at low temperature is well understood (according to GeSn phase diagram), the necessity of using reduced pressure to enable metastable GeSn growth has never been confirmed experimentally. This letter shows metastable GeSn epitaxial growth on Ge substrate, with Sn content up to $8 \%$, using an atmospheric pressure-chemical vapor deposition (AP-CVD) technique. We actually prove that reduced pressure is definitely not the key factor for growing GeSn alloys.

$200 \mathrm{~mm}$ blanket $1 \mu \mathrm{m} \mathrm{Ge} / \mathrm{Si}$ substrates were first realized with the procedure detailed in (Ref. 11). After a HF (2\%) wet clean the wafers were loaded again in a $200 \mathrm{~mm}$ ASM Epsilon-like CVD reactor. In order to allow GeSn growth at very low temperature, $\mathrm{Ge}_{2} \mathrm{H}_{6}$ was used as $\mathrm{Ge}$ precursor and $\mathrm{SnCl}_{4}$ as an innovative $\mathrm{Sn}$ precursor. $\mathrm{SnCl}_{4}$ is liquid at room

\footnotetext{
${ }^{\text {a)} E l e c t r o n i c ~ m a i l: ~ b e n j a m i n . v i n c e n t @ i m e c . b e . ~}$

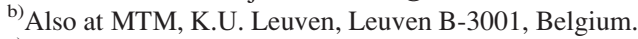

c) Also at IKS, K.U. Leuven, Leuven B-3001, Belgium.

d) Also at Center for Individual Nanoparticle Functionality, CINF, the Technical University of Denmark.
}

temperature and was evaporated by using a vapor station connected to the CVD reactor. The main advantage of using a $\mathrm{SnCl}_{4}$ liquid source, as compared to $\mathrm{SnD}_{4}$ (Ref. 12) (only $\mathrm{Sn}$ precursor so far reported in the literature for GeSn CVD) is the total absence of instability issues (gas consumption). Moreover, $\mathrm{SnCl}_{4}$ is a commercially available product. After a Ge pre-growth bake at $650{ }^{\circ} \mathrm{C}$, the growth temperature was fixed to $320^{\circ} \mathrm{C}$. Fig. 1 shows a cross section transmission electron microscope (TEM) picture with associated (224) $\mathrm{X}$-ray diffraction reciprocal space mapping (XRD RSM) of a $40 \mathrm{~nm}$ thick GeSn layer grown on a Ge substrate using atmospheric pressure. From Rutherford backscattering (RBS) measurements, a Sn content of $8 \%$ was determined in this layer. The TEM picture in Fig. 1(a) exhibits a defect free and high crystalline quality for the 40-nm-thick GeSn layer. Furthermore, the surface quality of the as-grown $\mathrm{Ge}_{0.92} \mathrm{Sn}_{0.08} /$ $\mathrm{Ge} / \mathrm{Si}$ heterostructure was investigated by reflection high energy electron diffraction (RHEED) analysis after ex-situ transfer to a MBE system. An annealing in ultrahigh vacuum up to $\sim 420^{\circ} \mathrm{C}$ resulted in an oxide-free GeSn surface showing a strong $(2 \times 1)$ surface reconstruction as seen on RHEED pattern along the [110] azimuth (Fig. 1(b)). Finally, the XRDRSM around the (2 2 4) Bragg reflections (Fig. 1(c)) demonstrat that the grown GeSn layer is fully strained on $\mathrm{Ge} / \mathrm{Si}$ (001) substrate. This result shows the fabrication of GeSn materials using an AP-CVD technique with a stable and commercially available $\mathrm{Sn}$ precursor.

The deposition temperature for the GeSn growth was kept low $\left(320^{\circ} \mathrm{C}\right)$ in order to allow $\mathrm{Sn}$ incorporation in $\mathrm{Ge}$ lattice without $\mathrm{Sn}$ precipitation nor agglomeration. ${ }^{10,13}$ Further anneals were then done after growth on the GeSn layers in order to assess their thermal stability. Anneals were performed in a rapid thermal anneal equipment at $400{ }^{\circ} \mathrm{C}$ and $500{ }^{\circ} \mathrm{C}$ for 10 and $30 \mathrm{~min}$ in pure $\mathrm{N}_{2}$. Fig. 2(a) first compares (004) omega-2 theta scans on the annealed samples with the as-grown one. Although a clear GeSn XRD peak is present on all the samples, we note that the GeSn peak fringes disappear for anneals realized at $500^{\circ} \mathrm{C}$. Some interface 
(a)
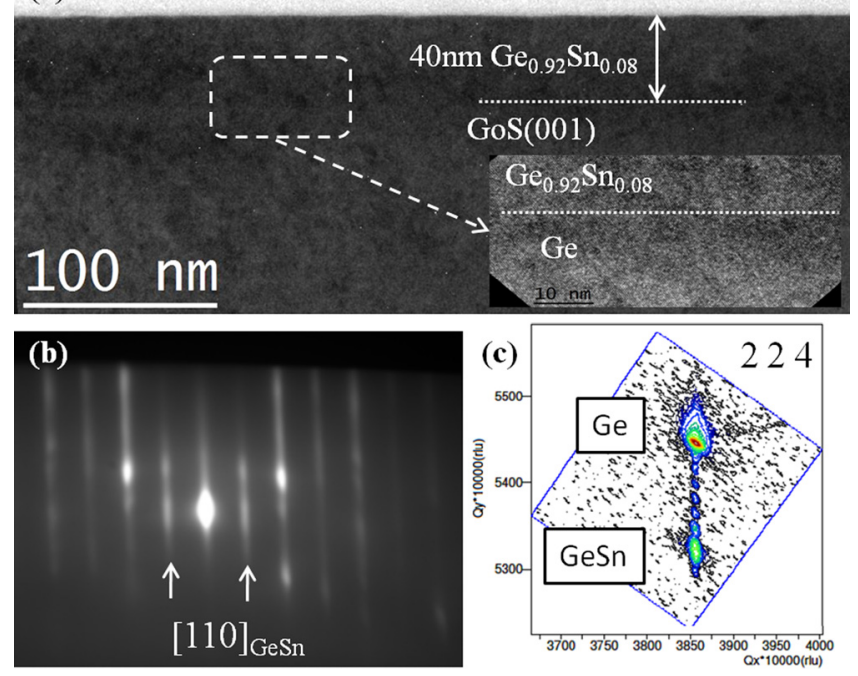

FIG. 1. (Color online) (a) Cross Section TEM of a $40 \mathrm{~nm}$ fully strained defect free GeSn layer on $1 \mu \mathrm{m} \mathrm{Ge/Si}$ buffer substrate with $8 \% \mathrm{Sn}$ grown with AP-CVD using combination of $\mathrm{Ge}_{2} \mathrm{H}_{6}$ and $\mathrm{SnCl}_{4}$. (b) RHEED diagram of the $\mathrm{Ge}_{0.92} \mathrm{Sn}_{0.08}$ surface after deoxidation in $\mathrm{UHV}$ at $420^{\circ} \mathrm{C}$. The pattern exhibits a strong $(2 \times 1)$ surface reconstruction along the $[110]_{\mathrm{Ge}}$ direction. (c) (224) XRD-RSM of the $40 \mathrm{~nm} \mathrm{Ge} \mathrm{Ge}_{0.92} \mathrm{Sn}_{0.08} / \mathrm{Ge}$ bilayer showing that GeSn is fully strained on Ge.

roughening is then likely to occur for samples annealed at temperatures as high as $500^{\circ} \mathrm{C}$. During optical microscope inspection (not shown here), we did not however notice any difference in surface morphology before and after anneals. The presence of clear GeSn XRD diffraction peaks confirms that the GeSn layer stays monocrystalline after anneals. Additional RSM scans (not shown here) moreover show that $\mathrm{GeSn}$ is also kept fully strained on Ge after anneals. We note that an important difference is observed on the XRD measurement (omega-2theta scan and also RSM) for the sample annealed at $500{ }^{\circ} \mathrm{C}$ during $30 \mathrm{~min}$. Both $\mathrm{GeSn}$ and Ge peaks are wider and a shift of the GeSn peak is observed. Being not identified, strain relaxation can then be the reason for such XRD peaks widening. Secondary ion mass spectroscopy (SIMS) was then realized on the as-grown and annealed $\mathrm{GeSn} / \mathrm{Ge}$ structures to detect possible Ge-Sn interdiffusion. Fig. 2(b) compares Sn SIMS profiles in the GeSn/Ge structures before and after anneals. The Sn slope is identical in all the samples except for the one annealed at $500{ }^{\circ} \mathrm{C}$ during $30 \mathrm{~min}$. A clear signature of $\mathrm{Sn}$ diffusion in $\mathrm{Ge}$ is observed, responsible for the difference observed in the previous XRD measurements. We note that this diffusion signature might be caused by $\mathrm{Sn}$ precipitation within the GeSn layer with this anneal condition. We then conclude that the metastable $8 \%$ $\mathrm{Sn}-\mathrm{GeSn}$ layer grown with our CVD approach survive to further thermal treatments at temperatures up to $500{ }^{\circ} \mathrm{C}$ and duration as long as $10 \mathrm{~min}$. No GeSn strain relaxation is observed after anneals but Ge-Sn interdiffusion (possibly enhanced by $\mathrm{Sn}$ precipitation) starts for longer anneals (30 min) at $500^{\circ} \mathrm{C}$.

In-situ $\mathrm{B}$ doped GeSn AP-CVD growth was also investigated by combination of $\mathrm{Ge}_{2} \mathrm{H}_{6}, \mathrm{SnCl}_{4}$, and $\mathrm{B}_{2} \mathrm{H}_{6}$ precursors. The growth of GeSn:B is of high interests for different kind of devices. ${ }^{7,14}$ Growth conditions were kept again at $320^{\circ} \mathrm{C}$ and atmospheric pressure, keeping the same $\mathrm{Ge}_{2} \mathrm{H}_{6} / \mathrm{SnCl}_{4}$
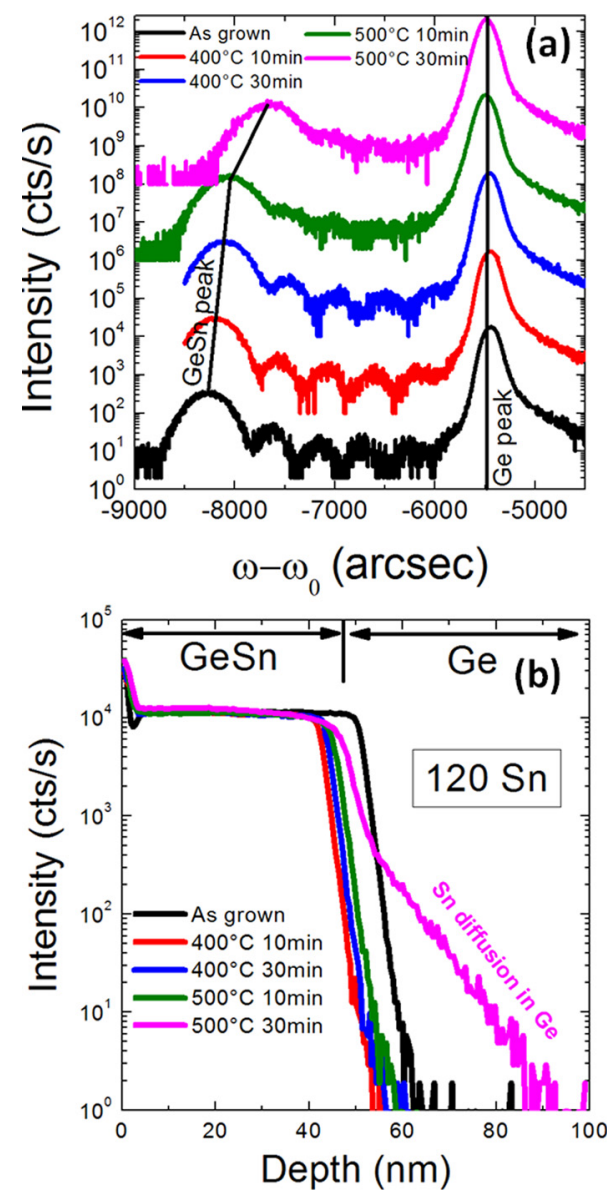

FIG. 2. (Color online) (a) Comparison of (004) omega-2 theta scan of asgrown and annealed $\mathrm{Ge}_{0.92} \mathrm{Sn}_{0.08} / 1 \mu \mathrm{m} \mathrm{Ge} / \mathrm{Si}$ with different anneal conditions: $400{ }^{\circ} \mathrm{C}-10 \mathrm{~min}, 400^{\circ} \mathrm{C}-30 \mathrm{~min}, 500^{\circ} \mathrm{C}-10 \mathrm{~min}$, and $500{ }^{\circ} \mathrm{C}-30 \mathrm{~min}$. (b) Comparison of $\mathrm{Sn}$ profile in the $\mathrm{Ge}_{0.92} \mathrm{Sn}_{0.08} / 1 \mu \mathrm{m} \mathrm{Ge} / \mathrm{Si}$ structure as function of anneal conditions: clear Sn diffusion in Ge is observed for an anneal performed at $500{ }^{\circ} \mathrm{C}$ for $30 \mathrm{~min}$.

flow ratio (giving 7\% $\mathrm{Sn}$ in GeSn alloy for undoped layers) and adding $\mathrm{B}_{2} \mathrm{H}_{6}$ with different partial pressures during the growth. This time, $80 \mathrm{~nm}$ GeSn:B layers were grown on $1 \mu \mathrm{m}$ slightly n-type doped $\left(1 \times 10^{17} \mathrm{~cm}^{-3}\right) \mathrm{Ge} / \mathrm{Si}$ blanket $200 \mathrm{~mm}$ wafers. Fig. 3(a) shows the B concentration, determined by SIMS, for $\mathrm{B}_{2} \mathrm{H}_{6}$ partial pressure varying from 0.18 to $3.7 \mathrm{mTorr}$. Surface roughening and loss of crystallinity (characterized by XRD) were observed for higher $\mathrm{B}_{2} \mathrm{H}_{6}$ partial pressured. The total $\mathrm{B}$ concentration in the $\mathrm{GeSn}$ layer increases almost linearly from $5 \times 10^{17}$ to $1.7 \times 10^{19} \mathrm{~cm}^{-3}$ with $\mathrm{B}_{2} \mathrm{H}_{6}$ partial pressure. The Sn content, determined by RBS (also shown in Fig. 3(a)), slightly decreases by incorporation of $\mathrm{B}$ (from $7.2 \%$ to $6.83 \%$ ) and goes down dramatically to $4.68 \%$ for the highest $\mathrm{B}_{2} \mathrm{H}_{6}$ partial pressure. The drop from $6.83 \%$ to $4.68 \%$ is attributed to $\mathrm{B}_{2} \mathrm{H}_{6}$ surface poisoning which lowers Sn incorporation, additionally to surface degradation. For partial pressures in between 0.18 and 1.85 mTorr, a competition between B and Sn might occur during the growth of ternary $\mathrm{GeSn}: \mathrm{B}$ alloys explaining a slight decrease in Sn content when B is incorporated. This competition actually occurs on the substitutional sites of the GeSn matrix. Using GeSn:B mobility values measured by micro-Hall measurements, ${ }^{15}$ reported in Fig. 3(b), and sheet resistances measured by the micro-four-point-probe (M4PP) technique, ${ }^{16}$ the active concentration of $\mathrm{B}$ in GeSn was 

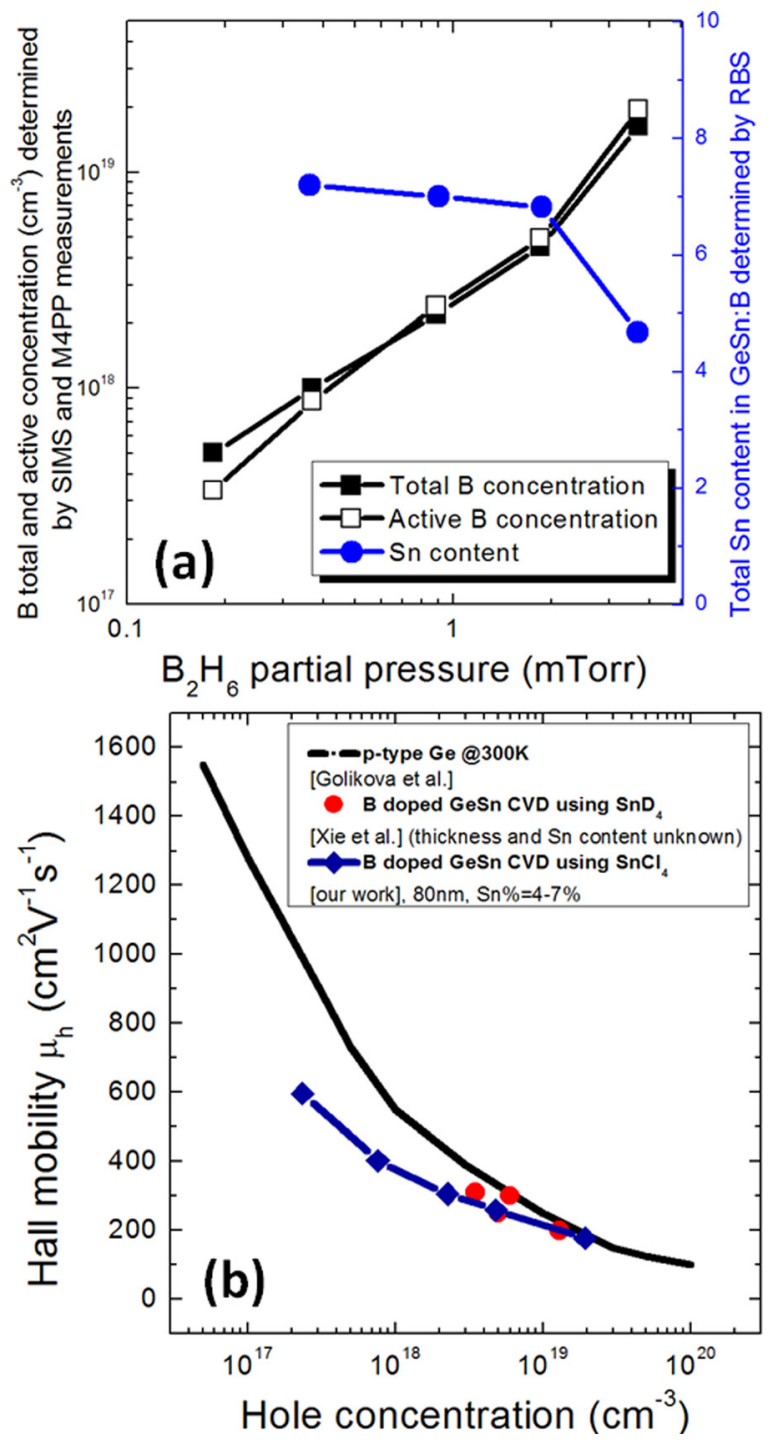

FIG. 3. (Color online) (a) Total B concentration (determined by SIMS), active B concentration (determined by M4PP measurements), and Sn content (determined by RBS) in GeSn:B layers grown on $1 \mu \mathrm{m}$ n-type Ge/Si structures as function of $\mathrm{B}_{2} \mathrm{H}_{6}$ partial pressure: $\mathrm{B}$ concentration increases linearly with $\mathrm{B}_{2} \mathrm{H}_{6}$ partial pressure while Sn content is decreasing. (b) Hole Hall mobility measurements in the GeSn:B layers grown as function of the B concentration showing slightly lower mobility values than in the p-Ge bulk case.

calculated and is reported as function of the $\mathrm{B}_{2} \mathrm{H}_{6}$ partial pressure, also in Fig. 3(a). The active concentration was calculated assuming GeSn dielectric constant and intrinsic carrier concentration equal to that of $\mathrm{Ge}$. We note that even for high $\mathrm{B}_{2} \mathrm{H}_{6}$ partial pressures, the $\mathrm{B}$ is $100 \%$ active in the insitu doped GeSn:B layers grown. This means that B is incorporated in the GeSn entirely in substitutional sites taking the place of either Ge or Sn atoms. Most likely, B prefers to occupy Sn sites in order to compensate the stress within the layer (B atoms are smaller than $\mathrm{Ge}$ atoms which are smaller than Sn atoms) which might explain the lower Sn incorporation for highly B doped GeSn layers. We note however that the increase of B concentration in the GeSn:B layer does not compensate entirely the decrease in Sn concentration which means that a lower $\mathrm{SnCl}_{4}$ partial pressure can also contribute to lower Sn incorporation. The Hall mobility values measured in the GeSn:B layers are compared with data from liter- ature on GeSn:B layers grown by Xie et al. ${ }^{17}$ Our values are in good agreement with Xie's measurements and show slightly lower Hall mobility values than mobilities in pure ptype Ge bulk materials. ${ }^{18}$ This mobility degradation is likely due to alloy scattering in the Ge-Sn system. For highly doped $\mathrm{GeSn}$ and $\mathrm{Ge}$, impurity scattering becomes the predominant cause for carrier scattering which explains that Ge and GeSn mobility values converge for $\mathrm{B}$ concentration higher than $3 \times 10^{18} \mathrm{~cm}^{-3}$.

In conclusion, this letter demonstrates the epitaxial growth of both undoped and in-situ B doped GeSn using a AP-CVD technique. We proved that reduced pressure is not mandatory and that GeSn can be made just by proper gas mixture of well chosen Ge and Sn precursors. This technique, using a production-like environment and commercially available gas precursors, opens new routes for research in group IV semiconductors. Sn can today definitely join $\mathrm{C}, \mathrm{Si}$, and $\mathrm{Ge}$ in the catalog of high potentials group IV materials.

The authors would like to acknowledge Voltaix and DOW Chemical for providing Digermane and Tin TetraChloride to imec, respectively, and Nagoya University for fruitful discussions on GeSn and for the use of their RTA equipments for this work. We would like moreover to thank the imec core partners within the Imec Industrial Affiliation Program on Logic.

${ }^{1}$ J. Kouvetakis, J. Menendez, and A. V. G. Chizmeshya, Annu. Rev. Mater. Res. 36, 497 (2006).

${ }^{2}$ G. H. Wang, E.-H. Toh, X. Wang, D. H. L. Seng, S. Tripathy, T. Osipowicz, T. K. Chan, K. M. Hoe, S. Balakumar, C. H. Tung, et al., Tech. Dig. - Int. Electron Devices Meet., 2007, 131.

${ }^{3}$ O. Nakatsuka, N. Tsutsui, Y. Shimura, S. Takeuchi, A. Sakai, and S. Zaima, Jpn. J. Appl. Phys. 49, 04DA10 (2010).

${ }^{4}$ Y. Chibane and M. Ferhat, J. Appl. Phys. 107, 053512 (2010).

${ }^{5}$ S. Takeuchi, Y. Shimura, O. Nakatsuka, S. Zaima, M. Ogawa, and A. Sakai, Appl. Phys. Lett. 92, 231916 (2008).

${ }^{6}$ C. Merckling, X. Sun, Y. Shimura, A. Franquet, B. Vincent, S. Takeuchi, W. Vandervorst, O. Nakatsuka, S. Zaima, R. Loo, and M. Caymax, Appl. Phys. Lett. 98, 192110 (2011).

${ }^{7}$ B. Vincent, Y. Shimura, S. Takeuchi, T. Nishimura, G. Eneman, A. Firrincieli, J. Demeulemeester, A. Vantomme, T. Clarysse, O. Nakatsuka, et al., Microelectron. Eng. 88, 342 (2011).

${ }^{8}$ J. P. Fleurial and A. Borshchevsky, J. Electrochem. Soc. 137, 2928 (1990).

${ }^{9}$ O. Gurdal, P. Desjardins, J. R. A. Carlsson, N. Taylor, H. H. Radamson, J.-E. Sundgren, and J. E. Greene, J. Appl. Phys. 83, 162 (1998).

${ }^{10}$ M. Bauer, J. Taraci, J. Tolle, A. V. G. Chizmeshya, S. Zollner, D. J. Smith, J. Menendez, C. Hu, and J. Kouvetakis, Appl. Phys. Lett. 81, 2992 (2002).

${ }^{11}$ R. Loo, G. Wanng, L. Souriau, J. C. Lin, S. Takeuchi, G. Brammertz, and M. Caymax, J. Electrochem. Soc. 157(1), H13 (2010).

${ }^{12}$ R. A. Soref, J. Kouvetakis, J. Tolle, J. Meenendez, and V. D'Costa, J. Mat. Res. 22, 3281 (2007).

${ }^{13}$ Y. Shimura, N. Tsutsui, O. Nakatsuka, A. Sakai, and S. Zaima, Jpn. J. Appl. Phys. 48, 04C130 (2009).

${ }^{14}$ J. Werner, M. Oehme, M. Schmid, M. Kaschel, A. Schirmer, E. Kasper, and J. Schulze, Appl. Phys. Lett. 98, 061108 (2011).

${ }^{15}$ D. H. Petersen, O. Hansen, R. Lin, and P. F. Nielsen, J. Appl. Phys. 104, 013710 (2008).

${ }^{16}$ D. H. Petersen, O. Hansen, T. B. Hansen, P. Boggild, R. Lin, D. Kjaer, P. F.Nielsen, T. Clarysse, W. Vandervorst, E. Rosseel, et al., J. Vac. Sci. Technol. B 28, C1C27 (2010).

${ }^{17}$ J. Xie, J. Tolle, V. R. D'Costa, C. Weng, A. V. G. Chizmeshya, J. Menendez, and J. Kouvetakis, Solid-State Electron. 53, 816 (2009).

${ }^{18}$ O. A. Golikova, B. Y. Moizhez, and L. S. Stilbans, Sov. Phys. Solid State 3, 10 (1962). 